\title{
The investigation adjustment status post-divorce and related factors in divorced women supported by the Birjand-based Relief Committee in 2018
}

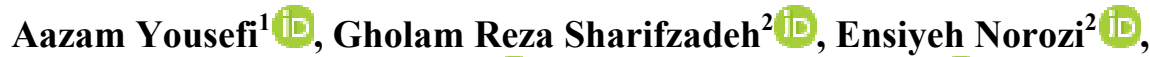 \\ Sara Sahranavard ${ }^{2}$ (D), Mohammad Reza Miri ${ }^{3}$
}

\footnotetext{
${ }^{1}$ Student Research Committee, Birjand University of Medical sciences, Birjand, Iran

${ }^{2}$ Social Determinants of Health Research Center, Birjand University of Medical sciences, Birjand, Iran

${ }^{3}$ Corresponding author; Social Determinants of Health Research Center, Birjand University of Medical sciences, Birjand, Iran Tel: +9832381651_Fax:31631651_E-mail:miri_moh2516@yahoo.com
}

Citation Yousefi A, Sharifzadeh GH, Norozi E, Sahranavard S, Miri MR . [The investigation adjustment status post-divorce and related factors in divorced women supported by the Birjand-based Relief Committee in 2018]. J Birjand Univ Med Sci. 2019; 26(4): 353-62. [Persian]
\end{abstract}

DOI http://doi.org/10.32592/JBirjandUnivMedSci.2019.26.4.107

Received: April 24, 2018

Accepted: July 21, 2019

\begin{abstract}
Background and Aim: Given the increasing divorce rate and vulnerability of divorced women in society, this study was aimed at the investigation adjustment status post-divorce and related factors in divorced women supported by the Birjand-based Relief Committee.

Materials and Methods: This descriptive-analytical study was performed on 160 divorced women covered by the Birjand Relief Committee by a multi-stage sampling method in 2018. A demographic questionnaire and the Fisher's Divorce adjustment Scale were used for data collection. Data were analyzed by SPSS software (version19) and analyzed by independent t-test, one-way ANOVA, and Tukey post-hoc tests at $\alpha=0.05$.

Results: The mean age of participants was $37.5 \pm 6.2$ years and the main cause of divorce in women was addiction of the spouse (44.4\%). The total mean score of adjustment in women was $331.1 \pm 56.3$, where $62.7 \%$ had poor adjustment and $37.3 \%$ had moderate adjustment. The mean score of adjustment in employed women was significantly higher than in household women $(p<0.001)$ and the adjustment score increased significantly as the education level increased $(p=0.027)$. The results also showed that there was no significant relationship between age, number of child, ex-spouse occupation, duration of the marriage, and years after divorce with post-divorce adjustment.

Conclusion: The results of the present study showed that divorced women, especially housewives and low-educated women, do not have a good adaptation status, therefore perform the interventions needed to improve the compatibility status it is suggested to officials and planners.
\end{abstract}

Key Words: Divorce; Adjustment; Divorced Women 


\title{
بررسى وضعيت ساز كارى يس از طلاق و عوامل مرتبط با آن \\ در زنان مطلقه تحت يوشش كميته امداد \\ شهر بيرجنل در سال
}

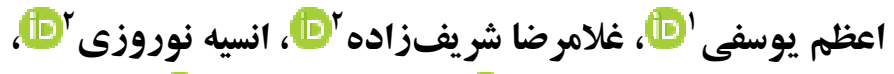

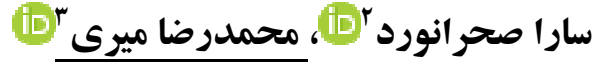

جَكيله

زمينه و هدف: با توجه به رشد آمار طلاق و آسيبيذيرى زنان مطلقه در جامعله، هدف از اين مطالعه، بررسى وضعيت ساز كارى يس

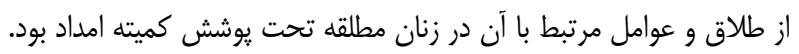

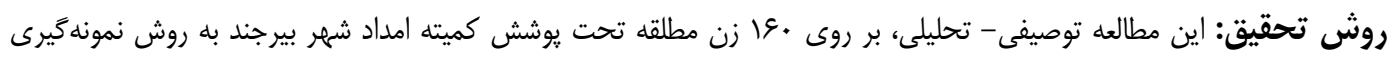

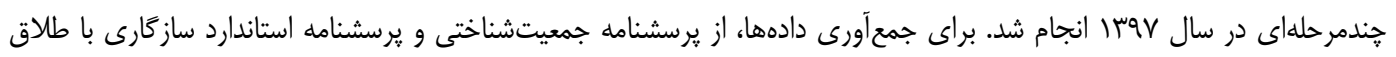

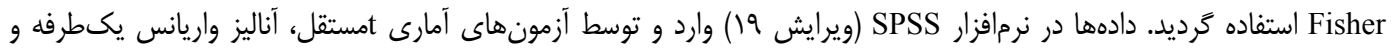

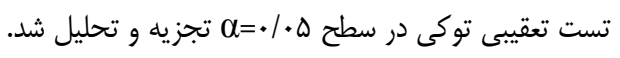

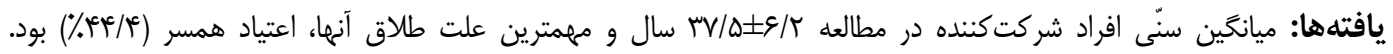

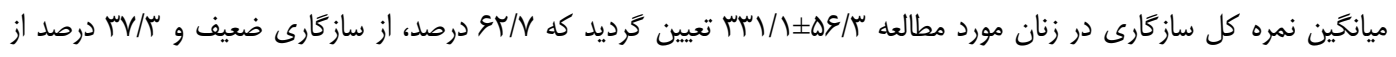

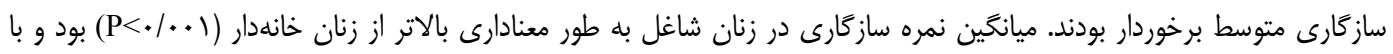

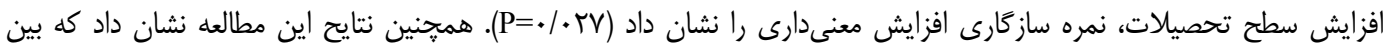

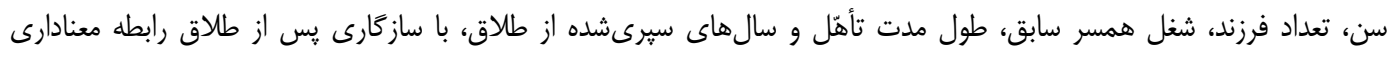
وجود نداشت. نتيجه كَيرى: نتايج مطالعه حاضر نشان داد كه زنان مطلقه بهخصوص زنان نان خانهان

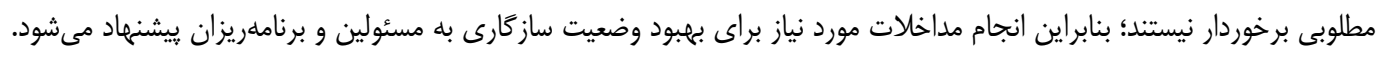
وازههاى كليدى: طلاق؛ سازكًاى؛ زنان مطلقه

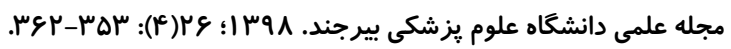

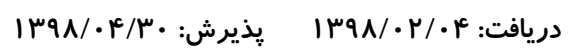


ييشبينى كند؛ به طورى كه شواهد نشان مىدهد بين

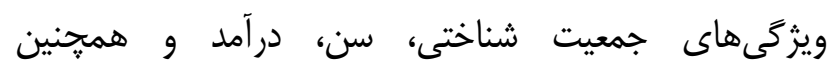

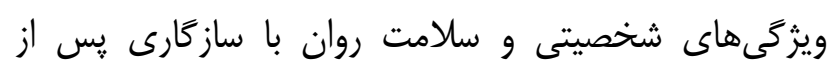
طلاق رابطه معنادارى وجود دارد (ه). علاوه بر اين، نتايج

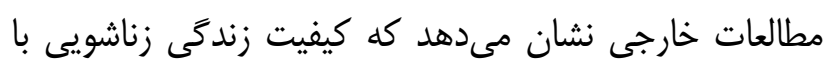

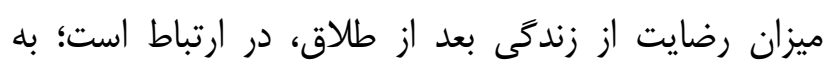

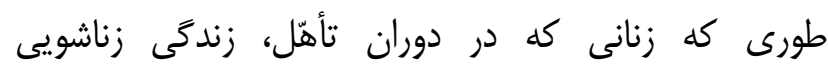

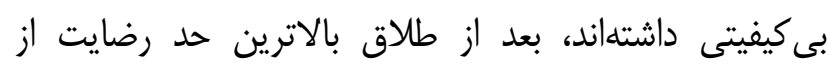

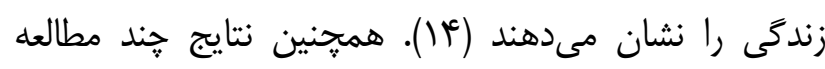
ديخر نشان داد كه سطح تحصيلات، وضعيت اشتغال و ميزان

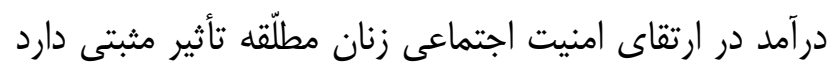

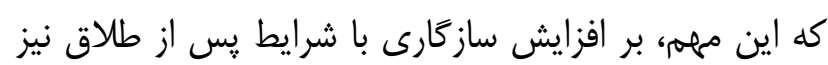

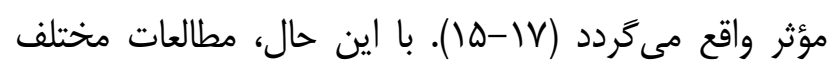

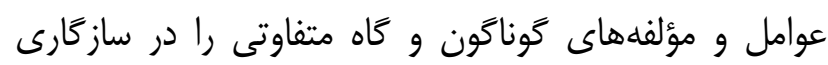
يس از طلاق مؤثر مىدانند؛ جرا كه بسيارى اعتقاد دارند كه

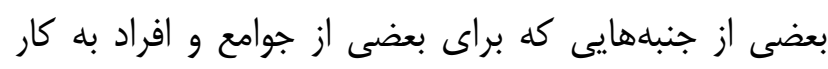

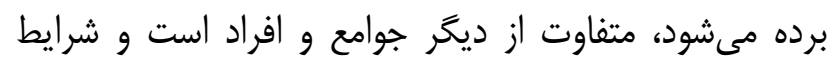

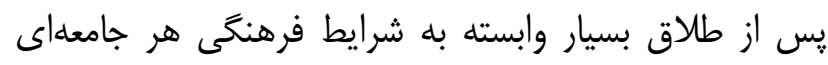

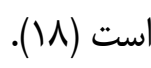

بنابراين با توجه به اهميت تأثير فرهنگ بر بر عوامل

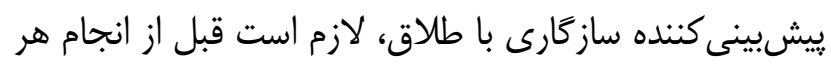

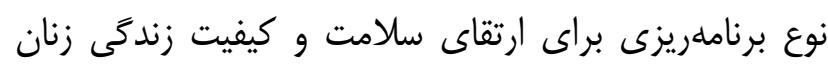

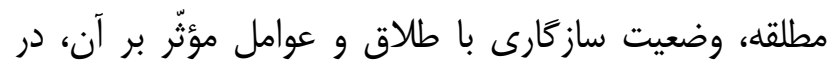
فرهنگ

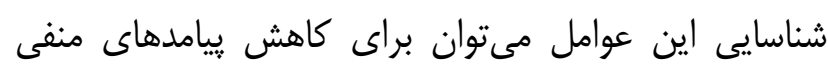

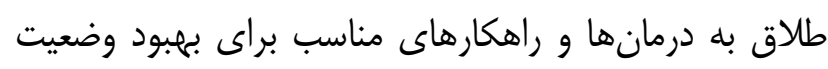
افراد مطلقه دست يافت (19، ه)؛ بنابراين با توحه به دماري كمبود

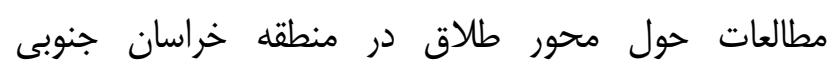

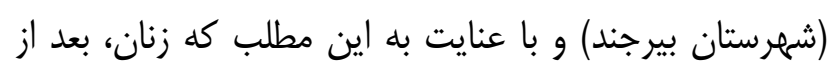

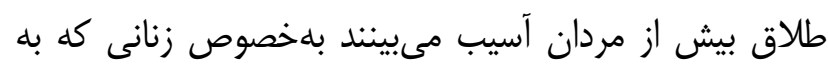
لحاظ مالى در مضيقه و تحت يوشش سازئ ازمانهاى مردي حمايتى

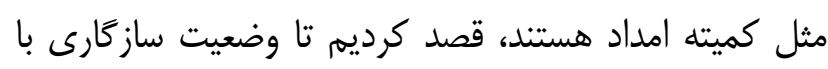

مقله طلاق يك حقيقت زندگى مدرن است (1) كه علاوه بر

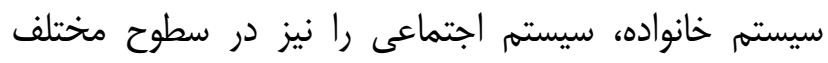

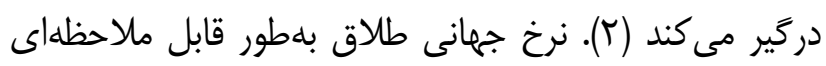
در كشورهاى صنعتى در حال افزايش است؛ در ايالات متحدهاه،

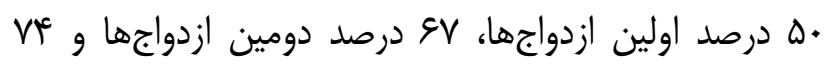

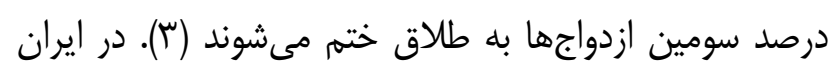

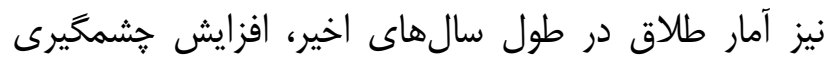

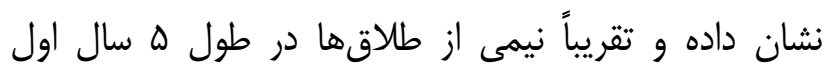

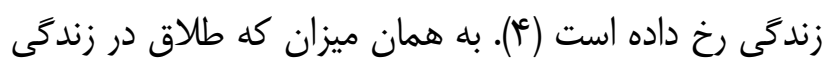

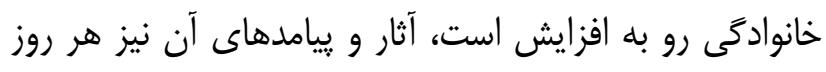

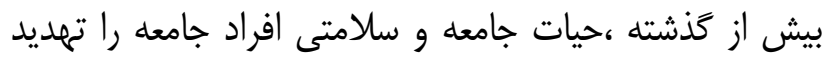

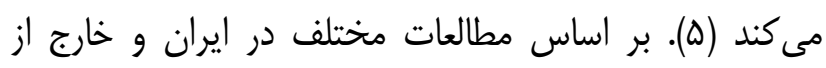

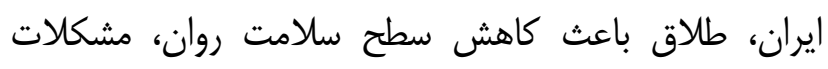

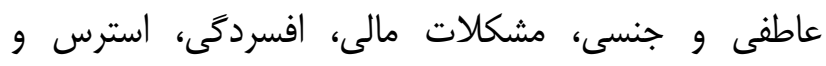
اضطراب و افكار خودكشى مىشود ( •(1- (و).

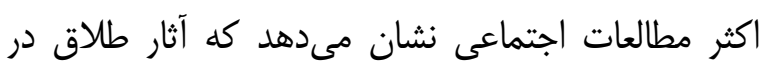

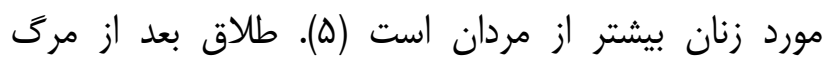

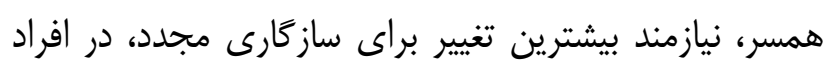

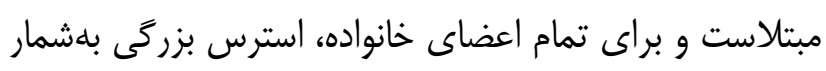

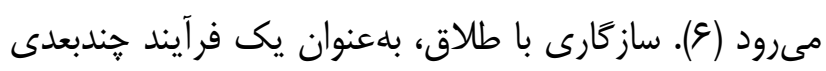
تعريف شده كه شامل مؤلّفههاى روانشناختى، اجتماعى و مالى لى

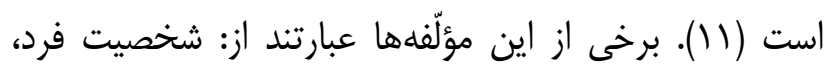

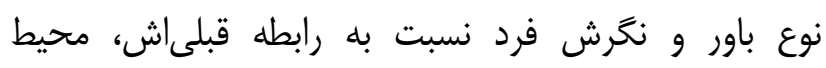

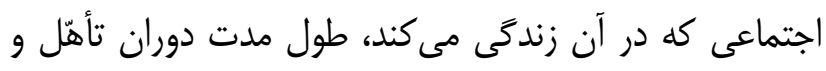

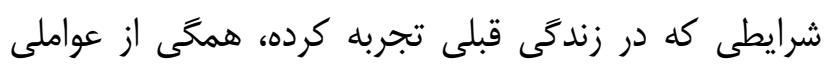

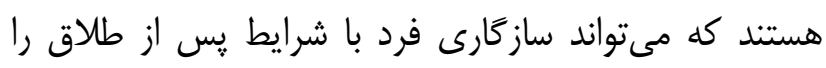

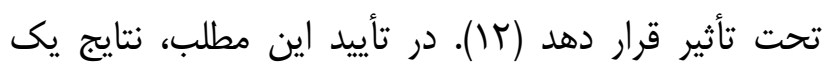

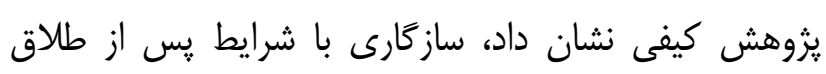

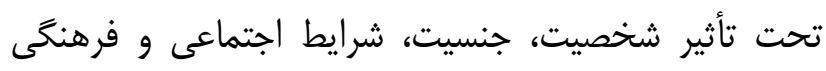

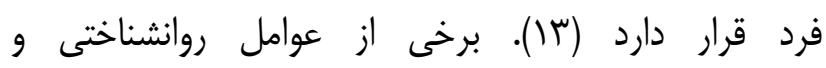

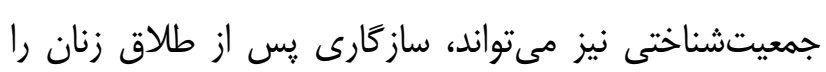


سؤالاتى در رابطه با مشخصات فردى همجون: سن، ميزان

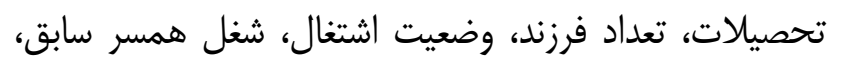

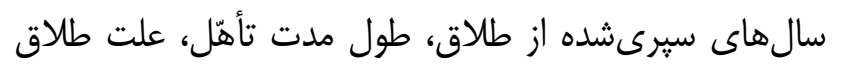

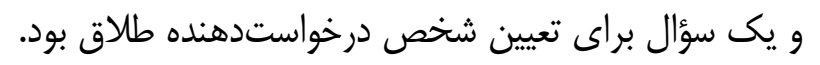

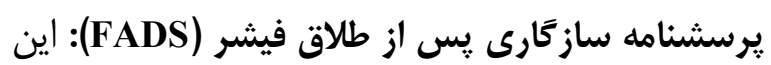

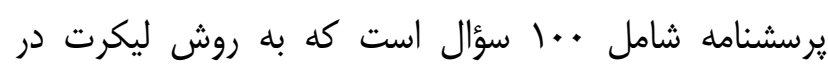

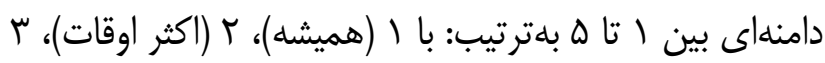

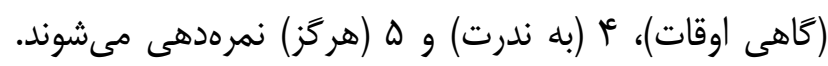

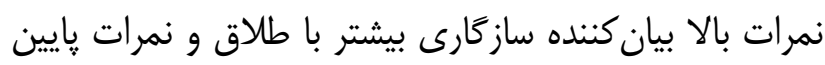

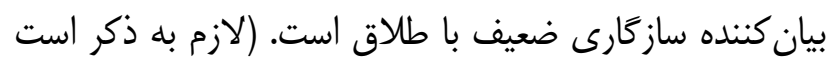
با توجه به معكوسبودن برخى سؤالات يرسشنامه، افزايش ساركات

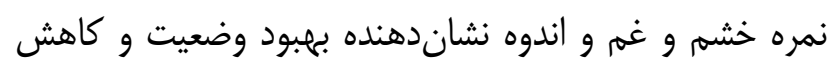
ميزان خشم و غم و اندوه در زنان مطلقه است.)

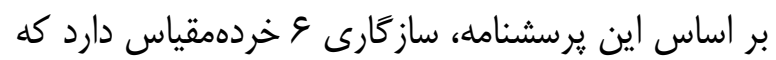

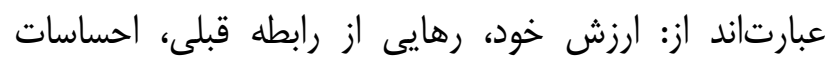

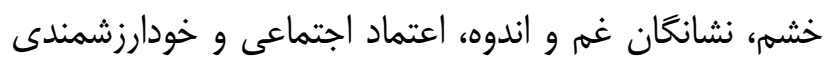

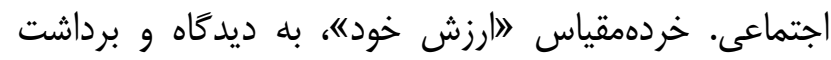

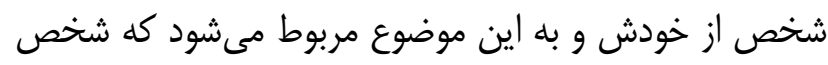

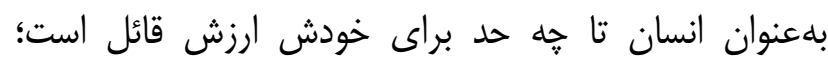

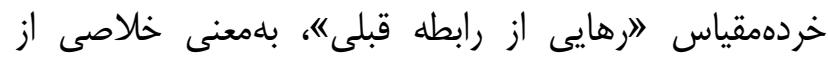

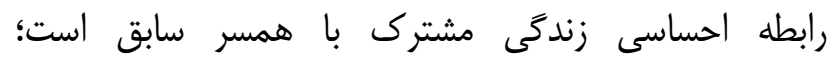
خردهمقياس لاحساسات خشمه كه منظور از آن، عنصر آصلى زئى

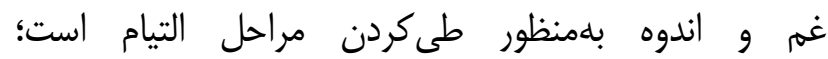
خردهمقياس "انشانگان غم و اندوه" حالت روانى است كه درد

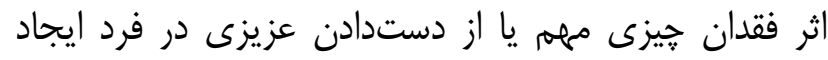

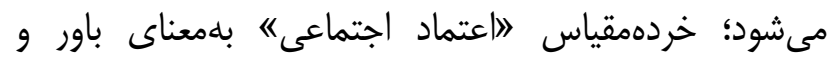

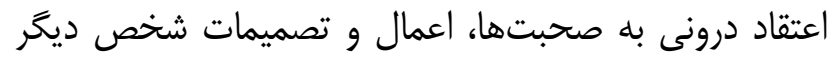
است و در نهايت خردهمقياس لخود ارزشمندى اجتماعى"،

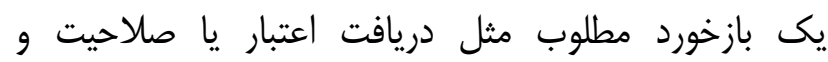

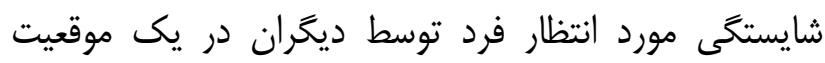

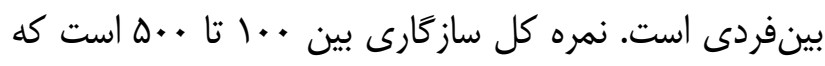

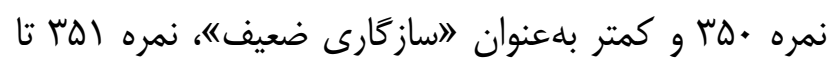

طلاق و عوامل جمعيتشناختى مؤثّر بر آن را با توجه به

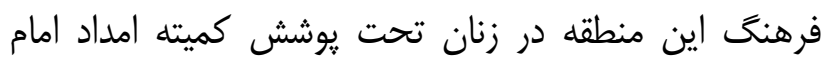

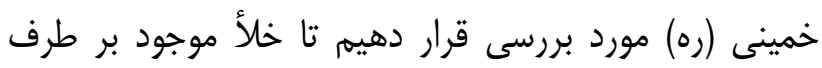

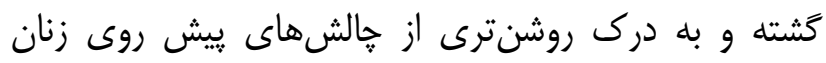
مطلقه دست يابيم.

\section{روش تحقيق}

مطالعه حاضر از نوع توصيفى - تحليلى و جامعه آمارى

شامل زنان مطلقه تحت يوشش كميته امداد امام خمينى (ره)

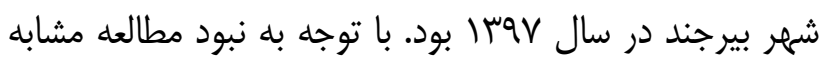

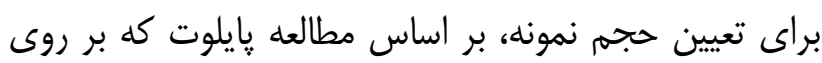

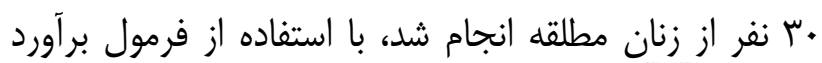
ميانخين d=1

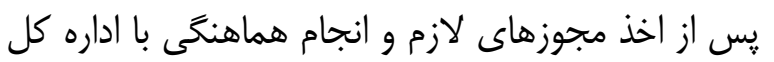

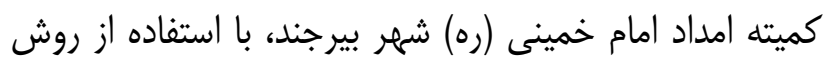

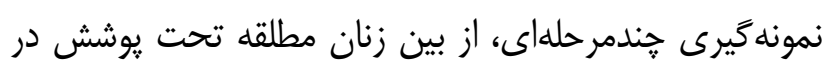

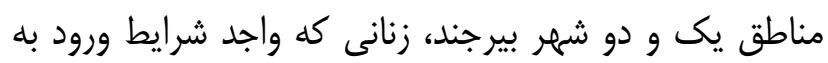

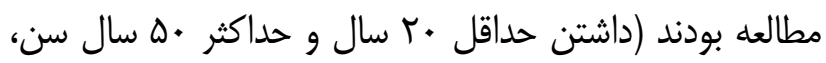

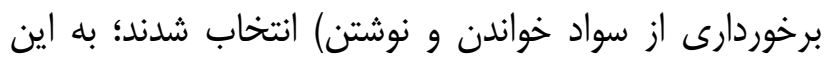

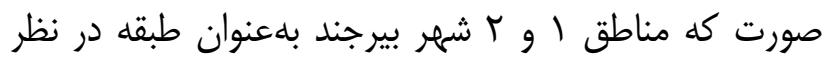

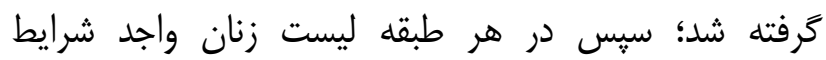
استخراج و بلصورت تصادفى سيستماتيك در هر طبقه نمونه

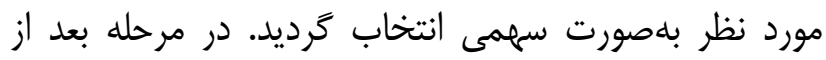
طريق تماس تلفنى با افراد انتخابشده ارتباط برقرار شد و و

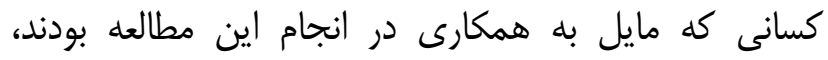
بلمنظور تكميل يرسشنامهاى مطالعه، براى حضور در جلسهاى فراخوان شدند.

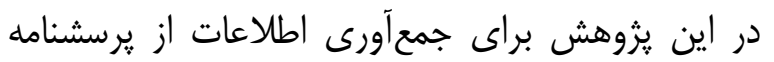

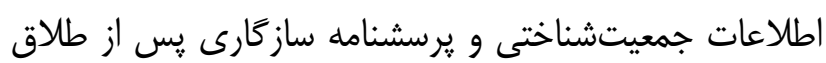
فيشر Fisher Divorce Adjustment Scale, FADS) استفاده شد. يرسشنامه اطلاعات جمعيتشناختى شامل 


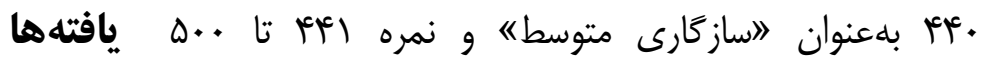

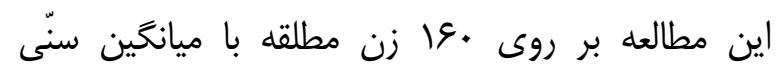

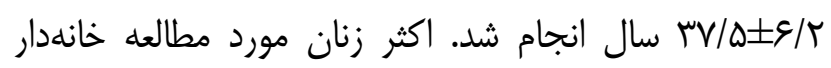

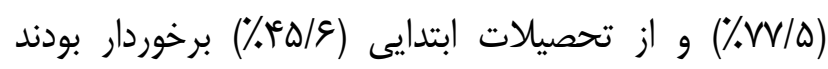

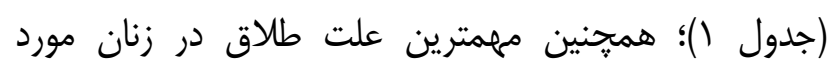

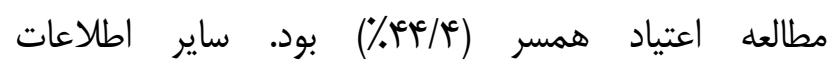
جمعيتشناختى در جدول يك ارائه شده است.

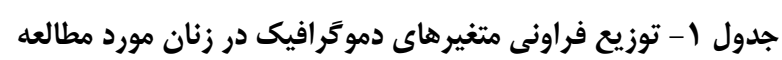

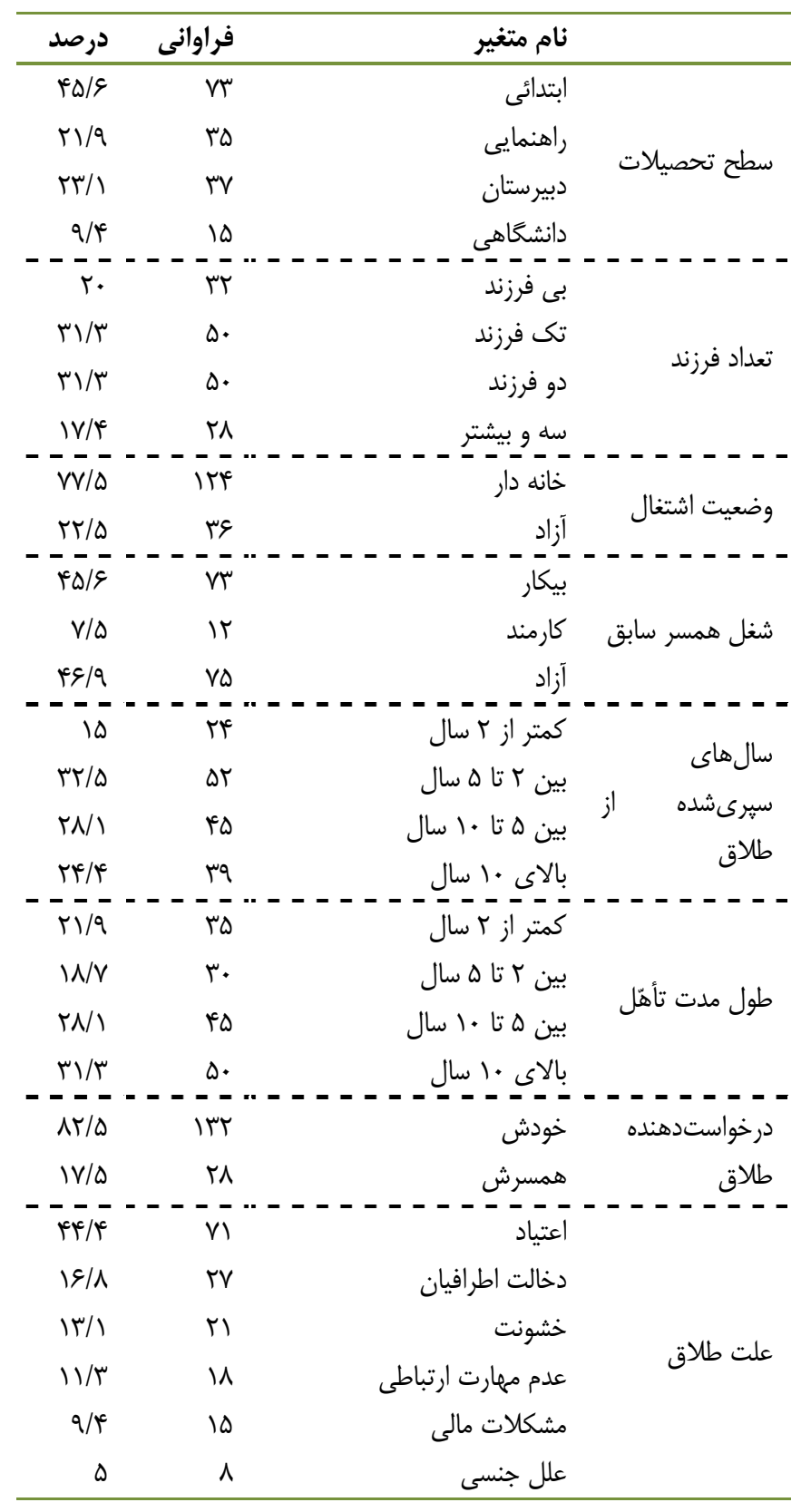

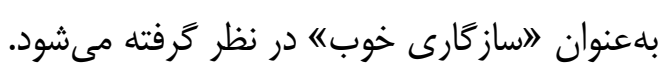

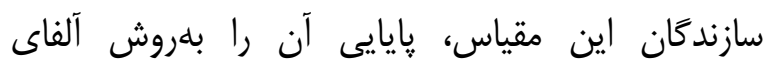

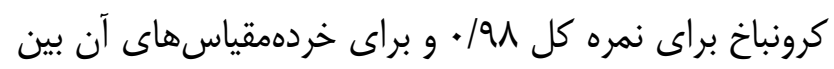
1AV

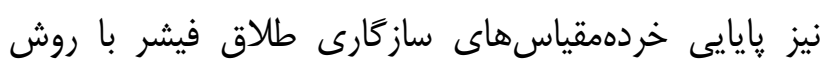

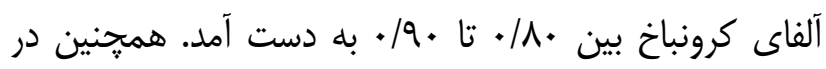

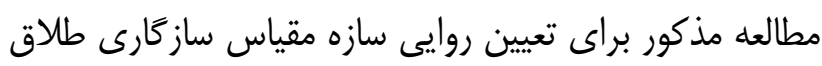

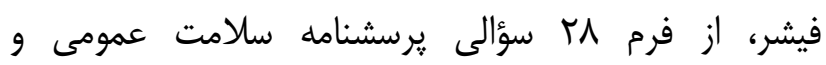
يرسشنامه عزت نفس روزنبرى استفاده كردند. در مطالعه آنها

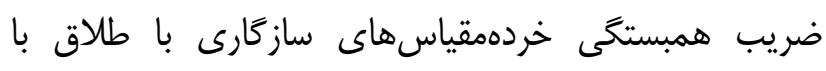

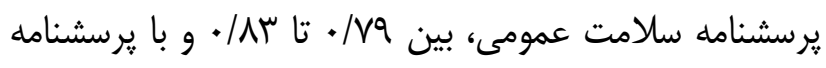

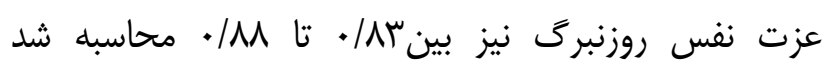

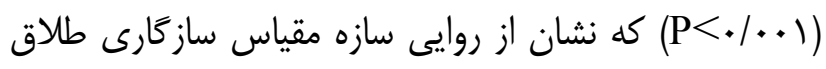

فيشر دارد (rآ) بلهنظور رعايت اخلاق در يروهش، ابتدا اهداف مطالعه

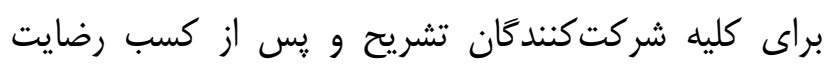

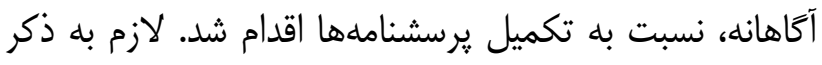
است اين مطالعه با كد Ir.bums.REC.1397.5 در كميته اخلاق دانشگاه علوم يزشكى بيرجند مورد تأييد قرار گرفته

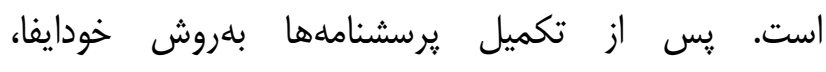

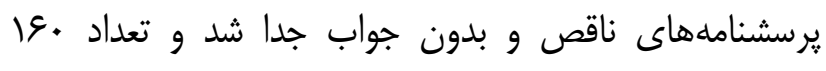

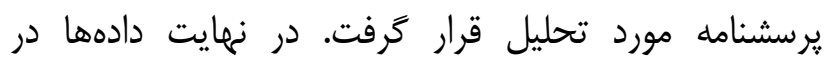

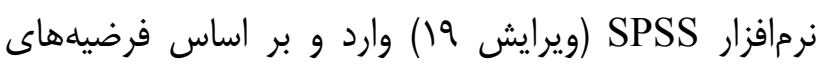

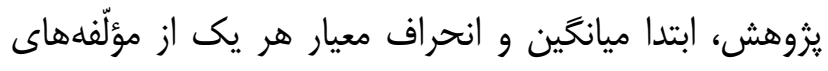

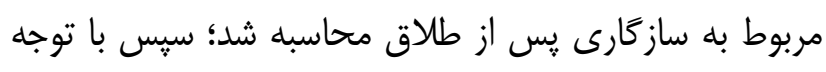

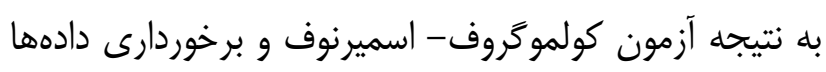

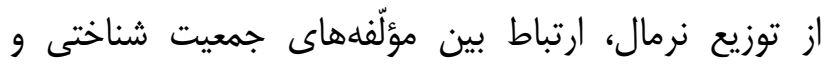

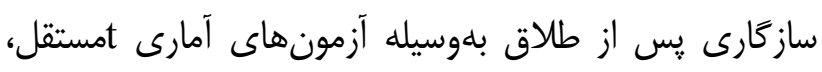

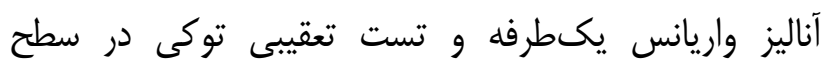

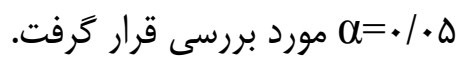




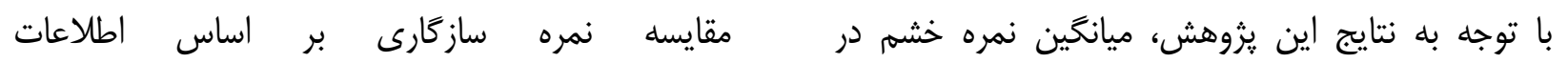

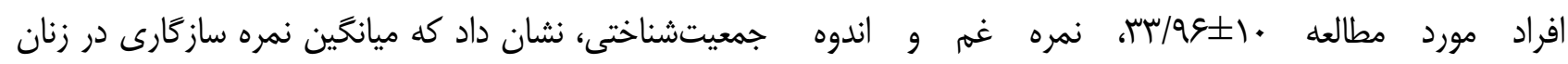

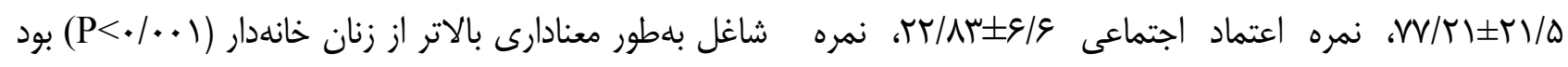
خودباورى س/ع|

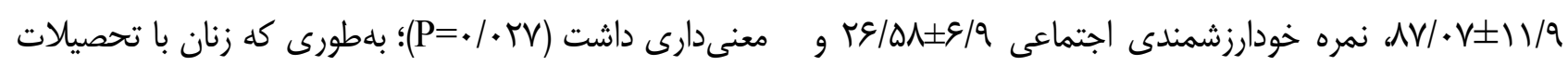

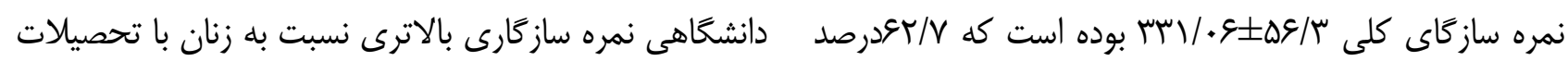

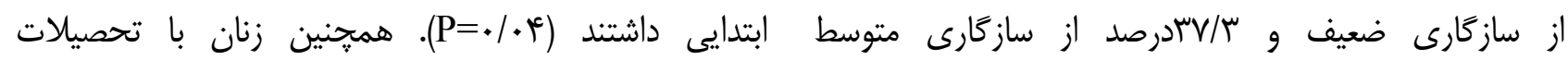

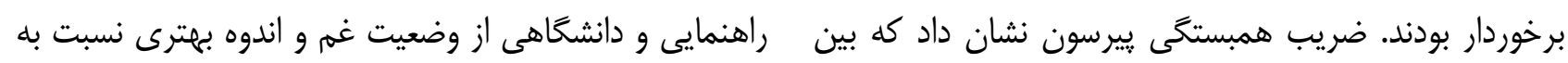

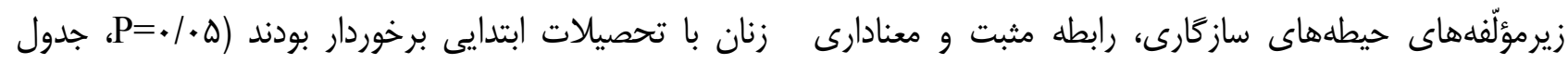

جدول r - برآورد ضر يب همبستكى بييرسون بين حيطههاى سازكًارى

\begin{tabular}{|c|c|c|c|c|c|c|c|}
\hline ساز كارى & خودارزشمندى & رهايى از رابطه & خودباورى & اعتماد اجتماعى & غم و اندوه & خشم & حيطهها \\
\hline $\mathrm{r}=. / 9)^{4}$ & $r=. / \% q$ & $\mathrm{r}=. / 19$ & $r=. / \mu \wedge$ & $\mathrm{r}=. / 4 \varepsilon$ & $r=. / 9$ & & \\
\hline 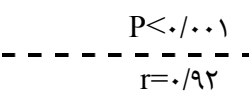 & $-\frac{\mathrm{P}<. / . \cdot 1}{\mathrm{r}=. / \overline{\mid q V}}-$. & 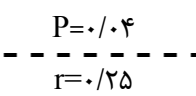 & 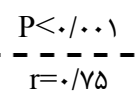 & 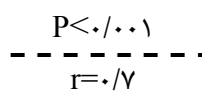 & $\mathrm{P}<\cdot 1 . .1$ & - & . - - - - - - - - - - \\
\hline $\mathrm{P}<\bullet / . \cdot 1$ & $\mathrm{P}<\cdot / . .1$ & $\mathrm{P}=\bullet / .+1$ & $\mathrm{P}<\cdot / . \cdot 1$ & $\mathrm{P}<\cdot / . .1$ & & - & غم و اندوه \\
\hline$---\bar{r}=\cdot / v g$ & $-\bar{r}=. / F^{-}-$. & $-\bar{r}=\overline{\cdot r}-\bar{r}$ & $-\bar{r}=.19$ & ------ & \multirow{2}{*}{-} & \multirow{2}{*}{-} & \multirow{3}{*}{ | - - - - - - - - - - - } \\
\hline $\mathrm{P}<\bullet / . .1$ & $\mathrm{P}<\bullet / . .1$ & $\mathrm{P}<\bullet / . .1$ & $\mathrm{P}<\cdot / \cdot \cdot 1$ & - & & & \\
\hline$----\bar{r}=\cdot / \Lambda \mathrm{V}$ & $-\bar{r}=. / \mathrm{Vr}-\cdot$ & 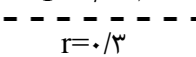 & ---- & ----- & --- & - - & \\
\hline $\mathrm{P}<\cdot / . .1$ & $\mathrm{P}<\cdot / . .1$ & $\mathrm{P}<\cdot / . .1$ & - & - & - & - & \multirow{2}{*}{ 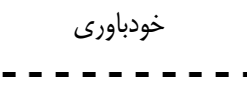 } \\
\hline$-\bar{r}=. / 89$ & $\mathrm{r}=. / \mathrm{re}^{\mathrm{e}}$ & & --- & --- & --- & -- & \\
\hline $\mathrm{P}<\cdot / \cdot \cdot 1$ & $\mathrm{P}=\cdot / \cdot r$ & - & - & - & - & - & رهايى از رابطه قبلى \\
\hline $\mathrm{r}=\cdot \mathrm{N}^{\mathrm{c}}$ & & & & & & & \multirow[b]{2}{*}{ خودارزشمندى اجتماعى } \\
\hline $\mathrm{P}<\cdot / \cdot \cdot 1$ & - & - & - & - & - & - & \\
\hline
\end{tabular}

جدول سـ- مقايسه ميانكَين نمره ساز ًَارى بر اساس اطلاعات جمعيتشناختى

\begin{tabular}{|c|c|c|c|c|c|c|c|c|c|}
\hline سازَارى & خودارزشمندى & رهايى از رابطه & خودباورى & اعتماعى اعتى & غم و اندوه & خشم & تعداد & \multicolumn{2}{|c|}{ نام متغير } \\
\hline$\Gamma \mid N / r \pm \varepsilon \cdot / \Delta$ & $r \Delta / \tau \pm V / \Delta$ & $\Lambda \Delta / V \pm I f / \mathcal{C}$ & $\Lambda 1 / T \pm 1 \Lambda / f$ & $r) / \Delta \pm \varepsilon / \varepsilon$ & $V / V \pm r r / r$ & $r r / V \pm 1 \cdot / l$ & V & ابتدايى & \\
\hline$r F \cdot / \mathcal{F} \pm F r / \Lambda$ & $\mathrm{rV} / \Delta \pm \varepsilon / \Delta$ & $\Lambda \bowtie / ৭ \pm \Lambda / \mathcal{C}$ & $\Lambda \bowtie / \xi \pm ו r / \vee$ & & 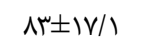 & $m p / q \pm q / q$ & ra & راهنمايى & \\
\hline & $r \varepsilon / 9 \pm \varepsilon / r$ & $19 / r \pm 1 \cdot / 4$ & $\Lambda \mu / \mu \pm I F / \Lambda$ & $r / \Lambda \pm \varepsilon / V$ & $V(N / \Lambda \pm r) / V$ & $\mathrm{~m} / \Lambda \pm q / q$ & rV & دبيرستان & \\
\hline & $r q / r \cdot \pm \Delta / r$ & १)/r $\pm V /$ । & $\wedge q / f \pm / f$ & $r \Delta / \Delta \pm \Lambda / r$ & $\Lambda \varepsilon / v \pm r \cdot / r$ & $\Gamma N / r \pm 1 \cdot / r$ & 10 & دانشخاهى & \\
\hline.$/ \cdot \mathrm{rV}$ &.$/ 1$ & r & . & .1 .9 & $\cdot 1 \cdot 1$ & $\cdot / F^{c}$ & - & P-value & \\
\hline$T K / / \pm \Delta F / g$ & $r \Delta / V \pm \varepsilon / \Lambda$ & $\Lambda \varepsilon / \gamma \pm 11 / 9$ & $\Lambda \cdot / \& \pm|\Delta / \Lambda|$ & rt位 & $V \mu / \Lambda \pm r / r / r$ & $r \mu \pm q / v$ & IMF & خانهدار & \\
\hline 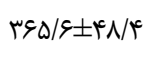 & $r q / \Lambda \pm \varepsilon$ & $9 \cdot \pm 11 / 9$ & $q \Psi / q \pm \mid r / r$ & $r \Delta / \Lambda \pm V / r$ & $M / q \pm I V / V$ & $\mathrm{rV} / \mathrm{I} \pm 1 \cdot / \Delta$ & ع ع & شاغل & وضعيت \\
\hline$<\cdot 1 . \cdot 1$ &.$/ .+1$ & .1 .9 & $\mathrm{P}<\cdot / \cdots 1$ & $\cdot / \cdot r$ & $\mathrm{P}<\cdot / \cdots 1$ & r. & - & P-value & \\
\hline
\end{tabular}


طلاق رابطه وجود دارد.

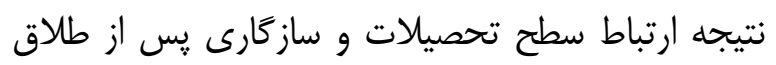

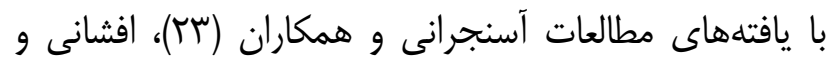

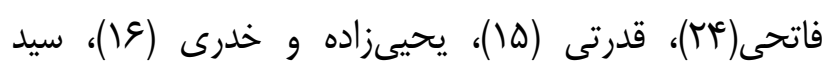

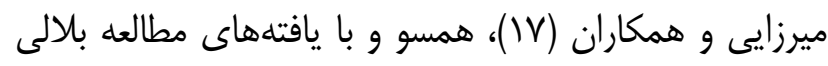

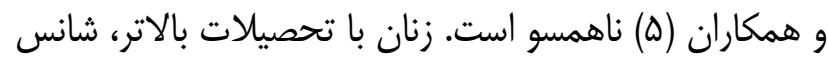

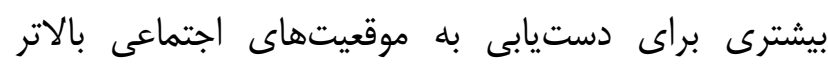

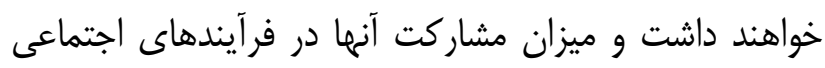

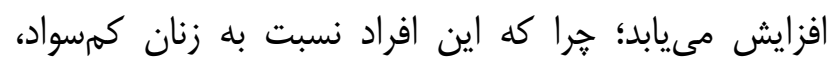
تجربه بحث و تبادلهاى علمى و غير علمى إنى بيشترى دارئ دارند؛

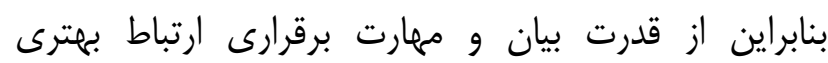

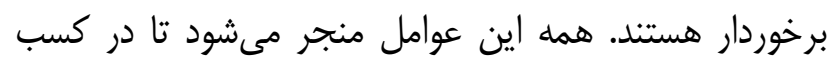
حمايتهاى اجتماعى موفقتر عمل كنند. تحصيلات نيازمند

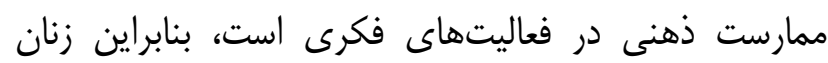

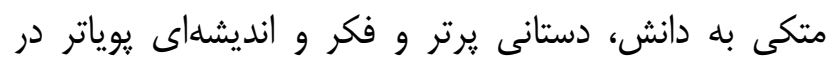

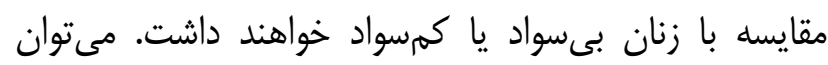

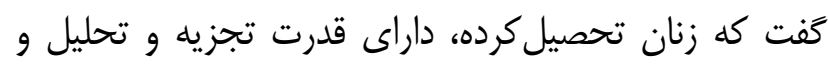

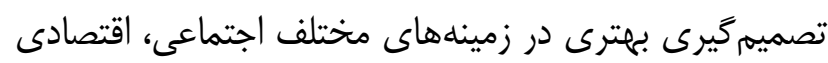

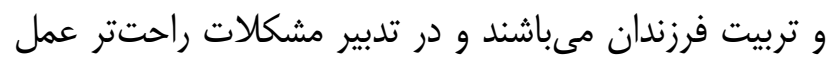

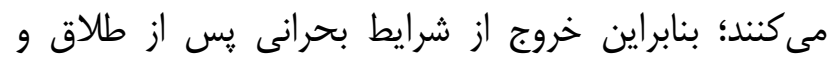

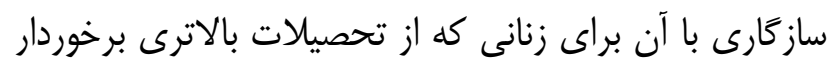
هستند، آسانتر خواهد بود.

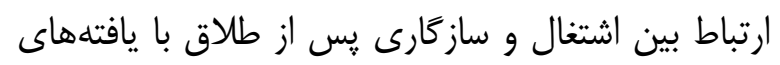

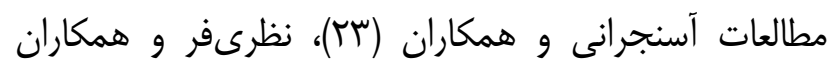

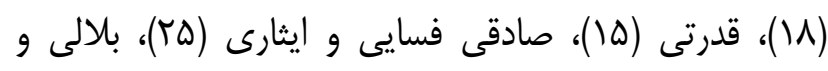

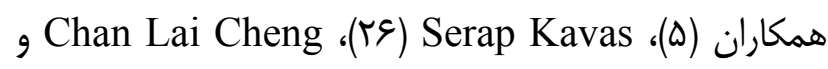
همسو مىباشد. طبيعى است كه در خانهماندن (TV) Pfeifer

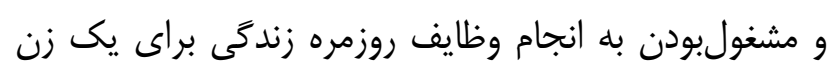

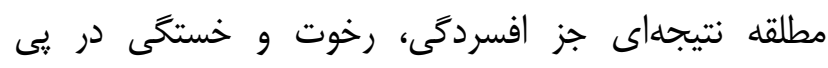

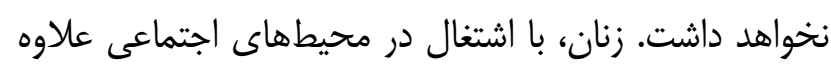

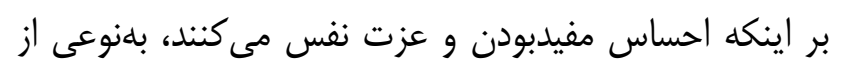

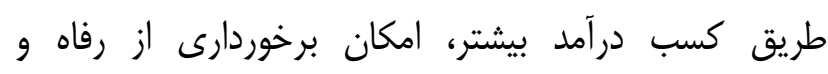

همجنين نتايح اين تحقيق نشان داد كه بين سن، تعداد

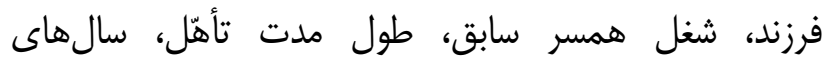

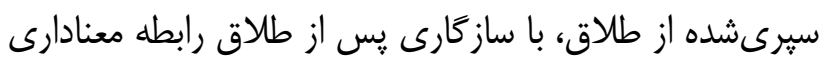

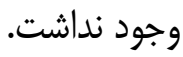

با توجه به رشد روز افزون طلاق و آسيبيذيرى زنان

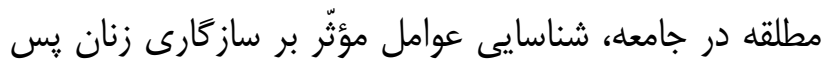

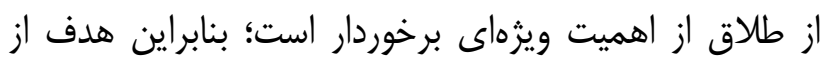

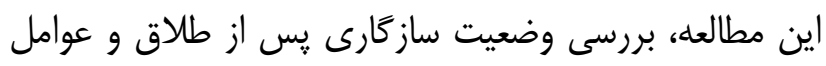
مرتبط با آن در زنان مطلقه تحت يوشش كميته امداد بود. تجزيه و تحليل نتايج اين مطالعه نشان داد كه اكثر زنان

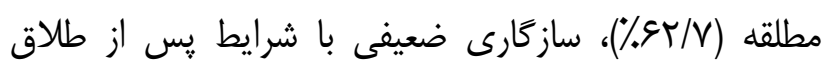

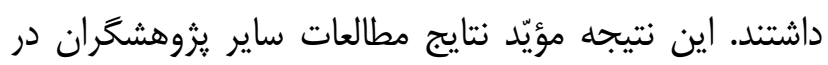

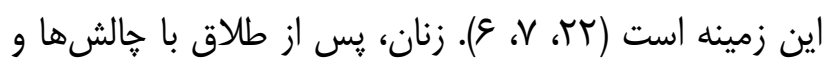

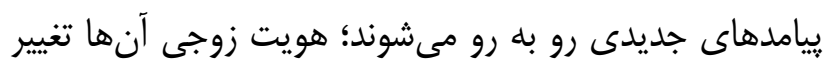

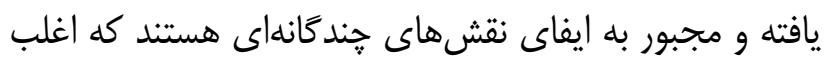

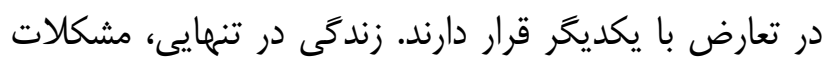

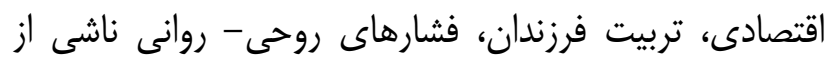

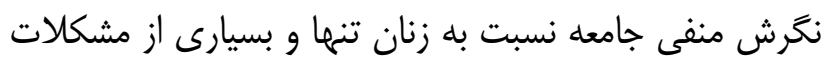

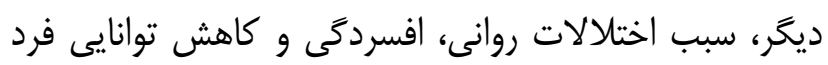

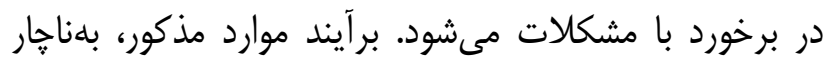

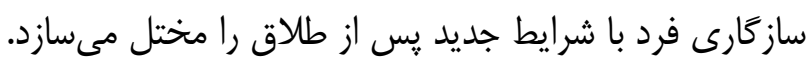

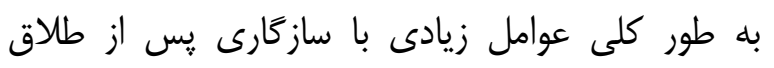
رابطه دارد كه مىتوان اين عوامل را در دو دسته عوامل غير باري

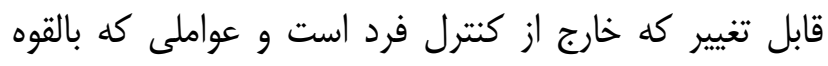

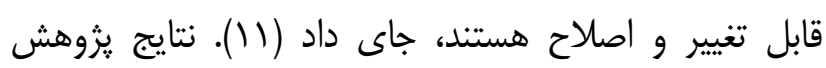

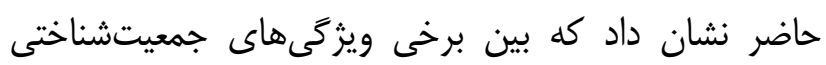

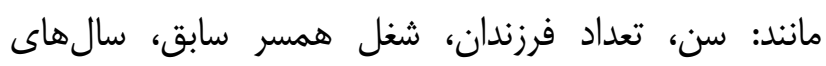

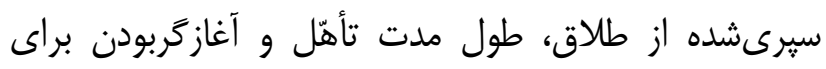

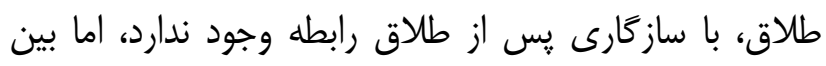

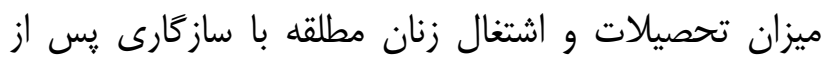


توصيه مىشود در مطالعات آتى، به نقش ساير عوامل از جمله عوامل روانشناسى و جامعلشناسى نيز توجه بيشترى شود.

\section{نتيجه كيرى}

با توجه به اينكه اشتغال زنان در خارج از خانه باعث

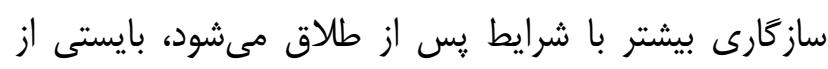

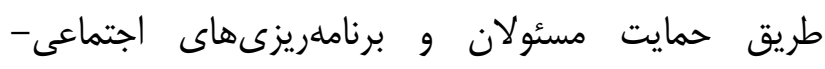

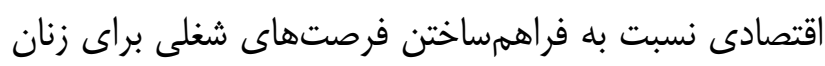
مطلقه اقدام شود؛ بهعنوان مثال، نهادهايى مثل كمان كميته فئه امداد

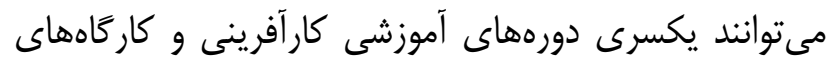

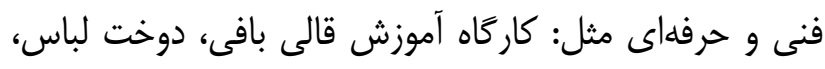

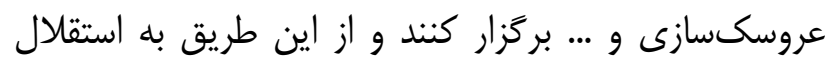

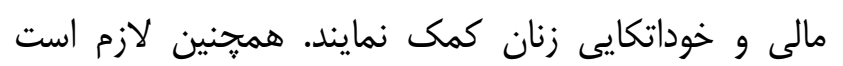

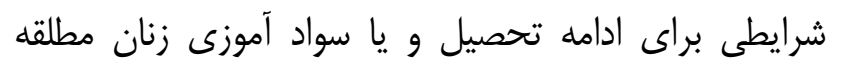

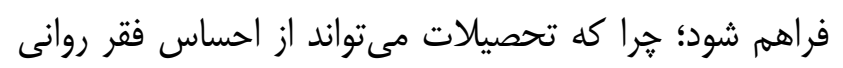

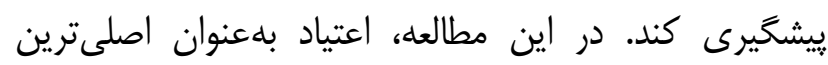

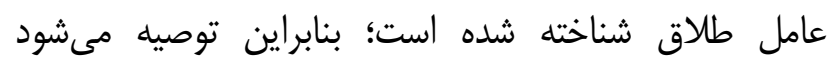

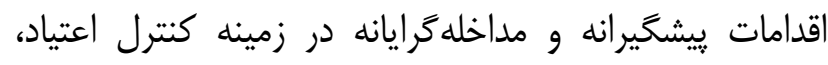
دقيقتر و جدىتر صورت كيرد.

\section{تقدير و تشكر}

اين مقاله حاصل ثاياننامه دانشجويى مصوب دانشكاه

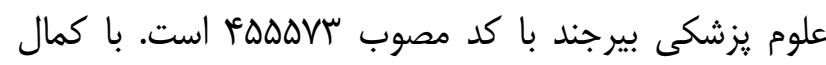
احترام، از مسئولين محترم اداره كل كل كميته امداد ادماد امدام خمينى

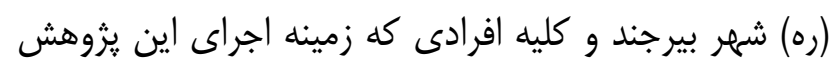
را فراهم كر دند، قدردانى مىنماييمه.

\section{تضاد منافع}

نويسندًان مقاله اعلام مىدارند كه هيجَّونه تضاد منافعى در يزوهش حاضر وجود ندارد.
تفريحات بيشترى هم براى آنها فراهم مىشود؛ از طرف ديكر

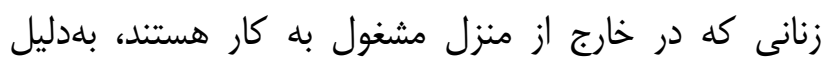

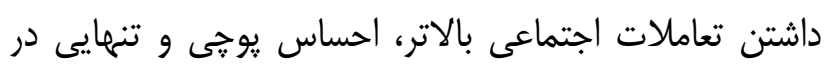

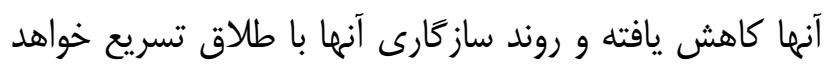

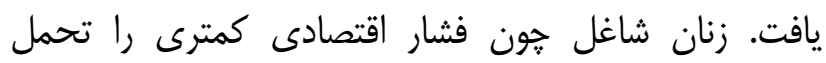

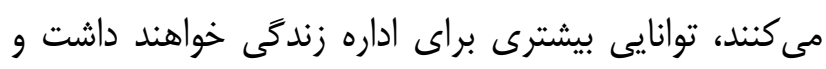

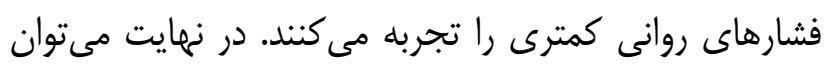

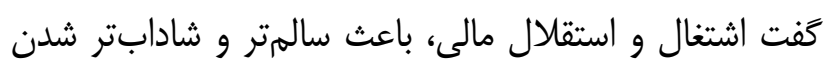
زندگى زنان مطلقه مىشود.

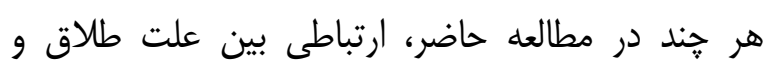

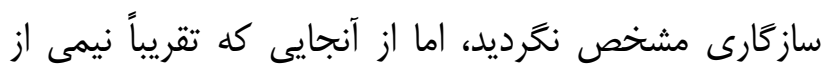

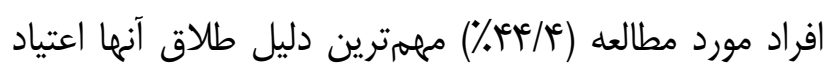

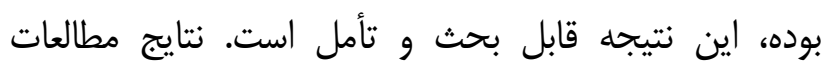

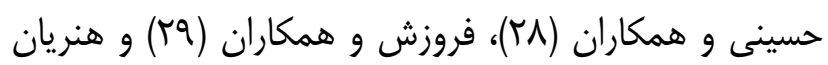

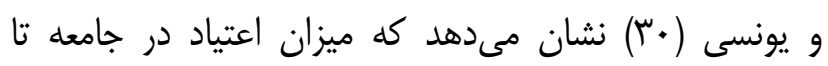
حدى بالا رفته و امروزه يكى از علل اصلى نابودى خانى خانوادهها،

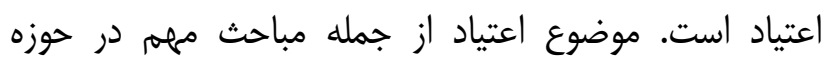

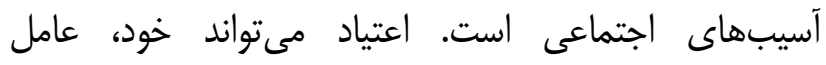

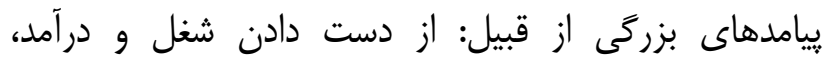

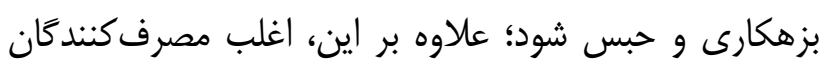

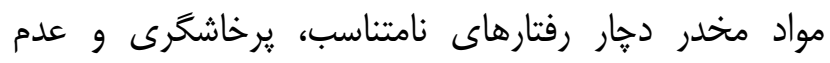
مسئوليتيذيرى مى شوند كه همه اين موارد در نهايت زمينه

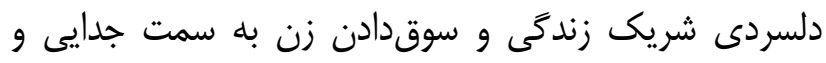
طلاق را فراهم مى كند. با توجه به دشوار بودن دسترسى به زنان مطان مطلقه در جامعله،

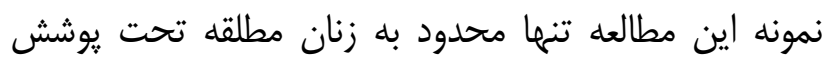

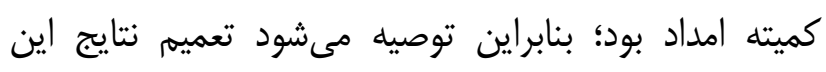

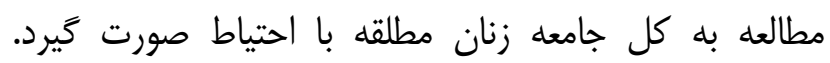

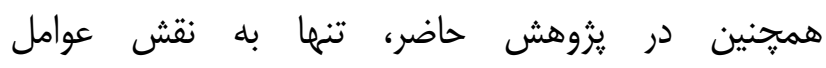
جمعيتشناختى در سازكارى با طلاق اشاره شده است كه 
1- Van Jaarsveld AW. Divorce and children in middle childhood: parents' contribution to minimise the impact [Dissertation]. Pretoria: University of Pretoria, Department of Social Work and Criminology; 2007. 163p.

2- Sheikhi K, Khosravi J, Gharibi H, Gholizadeh Z, Hosein zadeh M. Semantic understanding of divorce and discovery of its positive consequences (qualitative study). Journal of Family Counseling \& Psychotherapy. 2012; 2.1 (Special Issue): 64-78. [Persian]

3- Rahman MM, Giedraitis VR, Akhtar MT. The Social Sanction of Divorce: Who Ultimately Pay the Social Costs of Its Adverse Effects? Sociol Anthropol. 2013; 1(1): 26-33. DOI: 10.13189/sa.2013.010103

4- Asanjarani F, Jazayeri R, Fatehizade M, Etemadi O, De Mol J. The effectiveness of fisher's rebuilding group intervention on divorce adjustment and general health of Iranian divorced women. J Divorce Remarriage. 2018; 59(2): 108-22. DOI: 10.1080/10502556.2017.1375334

5- Balali T, Etemadi O, Fatehizade M. The Study of Relationship between Psychological factors and Demographic characteristics predicting Post Divorce Adjustment among Divorced Women in Isfahan. Counseling Culture and Psycotherapy. 2011; 2(5): 29-53. [Persian] DOI: 10.22054/qccpc.2011.5900

6- Jafari Nodooshan A, Zare H, Hosseini Hanzaei A, Poursalehi Navideh M, Zeini M. A Comparative Study of Mental Health, Adjustment, and Cognitive Emotion Regulation among Married Women and Divorcees in Yazd City. Journal of Woman and Society. 2015; 6(22): 1-16. [Persian]

7- Zaree F, Solhi M, Taghdisi MH, Kamali M, Shojaeezadeh D, Nejat S, et al. Post-divorce life experience in divorcee women: A qualitative study. Razi J Med Sci. 2014; 21(124): 13-26. [Persian]

8- Lavelle B, Smock PJ. Divorce and women's risk of health insurance loss. J Health Soc Behav. 2012; 53(4): 413-31. doi: $10.1177 / 0022146512465758$.

9- Zare R, Ghamari Givi H, Valizadeh B. Assessment of Mental Health in Divorcing Women Referred to Ardabil Legal Medicine Center. Iran J Forensic Med. 2016; 22(2): 87-94. [Persian]

10- Jang SN, Kawachi I, Chang J, Boo K, Shin HG, Lee H, et al. Marital status, gender, and depression: analysis of the baseline survey of the Korean Longitudinal Study of Ageing (KLoSA). Soc Sci Med. 2009; 69(11): 1608-15. DOI: 10.1016/j.socscimed.2009.09.007.

11- Mirzazadeh F, Ahmadi K, Fatehezadeh MAS. Examining the effectiveness of emotionally focused thrapy on postdivorce adjustment in women. Journal Of Family Counseling \& Spychotherapy. 2012; 1(4): 441-60. [Persian]

12- Vukalovich D, Caltabiano N. The effectiveness of a community group intervention program on adjustment to separation and divorce. J Divorce Remarriage. 2008; 48(3-4): 145-68. DOI: 10.1300/J087v48n03_09

13- Navabinejad S, Mohammadi R, Karami Y, Fallah E. Divorce means for divorced person perspective: A phenomenological qualitative study. Journal of Woman and Society. 2017; 8(3): 93-115. [Persian]

14- Bourassa KJ, Sbarra DA, Whisman MA. Women in very low quality marriages gain life satisfaction following divorce. J Fam Psychol. 2015; 29(3): 490-9. DOI: 10.1037/fam0000075.

15- Ghodrati S. Socio-economic Security of Divorced Women and its Relationship with Social Capital: A Case Study of Sabzevar City. Social Work Research. 2016; 2(8): 149-83. [Persian] DOI: 10.22054/rjsw.2016.8659

16- Yahyazadeh H, Khedri B. Social and Economic Factors Affecting the Societal Security of Women-Headed Households in Marivan City. Social Welfare. 2015; 15(56): 151-84. [Persian]

17- Seyed Mirzai SM, Abdollahi Z, Kamarbeigy Kh. Reviewing the Relationship Between Societal Factors and Societal Security of Women in Charge of Their Families (Case Study: Women in Ilam). Societal Security Studies. 2012; (28): 79-108. [Persian]

18- Nazarifar M, Sudani M, Khojasteh-Mehr R, Farhadirad H. Explanation of Factors Influencing Divorced Woman's Adjustment after Divorce: A Qualitative Study. J Qual Res Health Sci. 2017; 6(4): 477-92. [Persian] 
19- Zarei F, Merghati-Khoei ES, Taghdisi MH, Solhi M, Nejat S, Shojaeezadeh D, et al. Divorce from a divorcee woman's perspectives: A qualitative study. J Qual Res Health Sci. 2013; 2(3): 234-47. [Persian]

20- Fisher B, Bierhaus J. Facilitator's manual for rebuilding when your relationship ends. 1st ed. Berlin: Fisher Publishing Company; 1994.

21- Khojastehmehr R, Afshari F, Rajabi G. effectiveness of forgiveness training and post-divorce adjustment of women. womens studies. 2012; 10(1): 37-59. [Persian]

22- Symoens S, Van de Velde S, Colman E, Bracke P. Divorce and the multidimensionality of men and women's mental health: The role of social-relational and socio-economic conditions. Appl Res Qual Life. 2014; 9(2): $197-214$.

23- Asanjarani F, Jazayeri RS, Fatehizade M, Etemadi O, Demol J. Exploring factors affecting post-divorce adjustment in Iranian women: A qualitative study. Social Determinants of Health. 2017; 3(1): 15-25.

24- Afshani SAR, Fatehi E. An Investigation of Socio-cultural Factors influencing Women Householder Abilities in the City of Tabriz. Journal of Woman and Society). 2016; 7(3): 19-38. [Persian]

25- Sadeghi Fasaei S, Isari M. Post-Divorce Self-Redefining and Identity Building in Women. Women's Studies. 2013; 4(7): 111-38. [Persian]

26- Kavas S. Post divorce experience of highly educated and professional women [Dissertation]. Turkey, Ankara: Middle East Technical University; 2010. 344p.

27- Chan Lai Cheng J, Pfeifer JE. Postdivorce Adjustment in Singapore: Factors, Themes, and Positive Growth. J Divorce Remarriage. 2015; 56(6): 429-50. DOI: 10.1080/10502556.2015.1058657

28- Hoseini F, Rezapour M, Esmat saatlo M. The Study of Effective Factors in Increasing Divorce Rate (Case Study: Divorced Couples of Sarpolezahab Town). Quarterly Journal of Social Work. 2015; 4(2): 33-41. [Persian]

29- Forouzesh M, Mirhadi J, Mohammadi S, Javadi Vasigh H, Asadi K, Khojandi G, et al. Study of Factors Causing Divorce According to Women Referring to Forensic Centers of Hormozgan Province Comparing to A Control Group from March 2015 till March 2016. Iran J Forensic Med. 2018; 23(4): 271-81. [Persian]

30- Honarian M, Younesi J. The study of divorce reasons in Tehran family courts. Clinical Psychology Studies. 2011; 1(3): 125-53. [Persian] 